\title{
Clinical Features of Cardio-Renal Syndrome in a Cohort of Consecutive Patients Admitted to an Internal Medicine Ward
}

\author{
F. Fabbian ${ }^{1, *}$, M. Pala ${ }^{1}$, A. De Giorgi ${ }^{1}$, A. Scalone ${ }^{2}$, C. Molino ${ }^{1}$, F. Portaluppi ${ }^{1}$, D.P. Mikhailidis ${ }^{3}$ \\ and R. Manfredini ${ }^{1}$
}

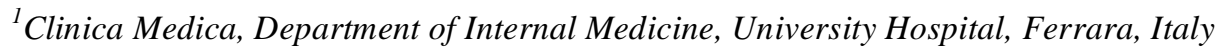

${ }^{2}$ Department of Cardiology, University Hospital, Ferrara, Italy

${ }^{3}$ Department of Clinical Biochemistry (Vascular Disease Prevention Clinics), University College London Medical School, London, UK

\begin{abstract}
Introduction: Cardiorenal syndrome (CRS) is a disorder of the heart and kidney whereby interactions between the 2 organs can occur. We recorded the clinical features of CRS in patients consecutively admitted to an Internal Medicine ward.

Patients and Methods: We retrospectively analyzed the anthropometric, history, clinical, biochemical and treatment characteristics in 438 out of 2,998 subjects (14.6\%) admitted to our unit (from June 2007 to December 2009), diagnosed with CRS, according to Acute Dialysis Quality Initiative (ADQI) recommendations. Estimated glomerular filtration

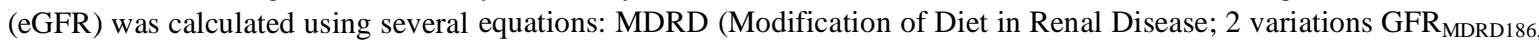

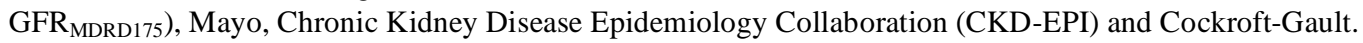

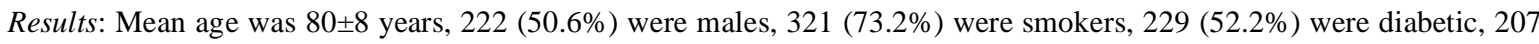
$(47.2 \%)$ had a history of acute myocardial infarction, 167 (38.1\%) had angina, 135 (30.8\%) were affected by cerebrovascular disease, $339(77.3 \%)$ had peripheral arterial disease. CRS was type 1 in 211 cases (48.2\%), type 2 in 96 (21.9\%), type 3 in $88(20.1 \%)$, type 4 in $29(6.6 \%)$ and type 5 in $14(3.2 \%)$. eGFR, calculated by different formulae, ranged between 31 and $36 \mathrm{ml} / \mathrm{min} / 1.73 \mathrm{~m}^{2}$. GFR was lower in CRS type 3 than in the other types, and the values ranged between 24 and $27 \mathrm{ml} / \mathrm{min} / 1.73 \mathrm{~m}^{2}$. Mean hospital length-of-stay (LOS) was $9.8 \pm 6.3$ days. Diuretics were the most prescribed medication $(78.7 \%)$; only 5 patients underwent haemodialysis.

Conclusions: CRS is common, especially in the elderly. CRS Type 1 was the prevalent subset and patients had stage 3-4 renal insufficiency. Results obtained from the GFR equations were similar although the Mayo equation tended to overestimate the eGFR.
\end{abstract}

Keywords: Cardio-renal syndrome, heart failure, chronic kidney disease, renal function, heart disease.

\section{INTRODUCTION}

Interactions between kidney and heart have recently been defined and classified by the consensus conference of the Acute Dialysis Quality Initiative (ADQI) [1]. The clinical relevance of cardio-renal syndrome (CRS) is still a matter of debate, and the time course of kidney-heart interaction is not clear. This is probably because the physiological, biochemical and hormonal relationships between the heart and the kidney are complex [2]. It follows, that the management of patients with CRS could sometimes be unsuitable.

Understanding the pathophysiology of CRS might suggest therapies that can interrupt dangerous feedback loops. However, information regarding the clinical features of different types of CRS in Internal Medicine settings is

*Address correspondence to this author at the Clinica Medica, Department of Clinical and Experimental Medicine, University Hospital, Corso Giovecca, 203, I-44100 Ferrara, Italy; Tel: +39 0532 236374; Fax: +39 0532 238539;

E-mail: f.fabbian@ospfe.it very limited. Thus, we identified patients with CRS admitted to an Internal Medicine ward, in order to characterize the disorder and assess its impact in clinical practice.

\section{PATIENTS AND METHODS}

This retrospective study was performed under the terms of the Declaration of Helsinki.

Adult Caucasian patients $(n=438)$, selected from 2998 subjects consecutively discharged from our 30-bed medical ward from June 2007 to December 2009 with CRS, were evaluated. The reason for hospitalization was cardiovascular disorder in $26 \%$, pulmonary disorder in $30 \%$, digestive disorder in $20 \%$ and other disorders (including urogenital, metabolic, neurologic, osteoarticular) in $24 \%$. CRS was diagnosed according to the ADQI criteria [1], and patients were thereafter classified according to the 5 types (see below). Congestive heart failure (CHF) was diagnosed according to the European Society of Cardiology criteria [3]. Smoking and diabetes history, ischaemic heart disease (IHD) 
and chest pain, peripheral arterial disease (PAD), cerebrovascular disease and hospital length-of-stay (LOS) were also recorded.

IHD, cardiovascular disease (CVD) and PAD were ascertained based on history and/or presence of any combination of specific signs, previous diagnosis or treatment. For each patient, renal function was evaluated by estimated glomerular filtration rate (eGFR) using the following equations $(\mathrm{SCr}=$ serum creatinine):

Modification of Diet in Renal Disease (MDRD) 186 formula [4]: $\mathrm{GFR}_{\mathrm{MDRD} 186}=186 \times(\mathrm{SCr})^{-1.154} \mathrm{x}$ [age $(\text { years })^{-0.203} \mathrm{x}$ (0.742 if female) $\mathrm{x}$ (1.212 if African-American)

$\mathrm{MDRD}_{175}$ formula [5]: $\mathrm{GFR}_{\mathrm{MDRD} 175}=175 \mathrm{x}(\mathrm{SCr})^{-1.154} \mathrm{x}$ [age (years) $)^{-0.203} \times(0.742$ if female $) \times(1.212$ if AfricanAmerican)

Mayo Clinic Quadratic formula [6]: GFR MAYO $_{\text {ayo }}$ $\exp \left[1.911+5.249 / \mathrm{SCr}-2.114 / \mathrm{SCr}^{2}-0.00686 \mathrm{x}\right.$ age (years) -0.205 (if female)]

Chronic Kidney Disease Epidemiology Collaboration (CKD-EPI) formula [7]:

- If female and if $\mathrm{SCr} \leq 0.7 \mathrm{mg} / \mathrm{dl}:$

$\mathrm{GFR}_{\mathrm{CDK}-\mathrm{EPI}}=144 \times \mathrm{SCr} / 0.7^{-0.329} \times 0.993^{\text {age }}$

- If female and if $\mathrm{SCr}>0.7 \mathrm{mg} / \mathrm{dl}$ :

$\mathrm{GFR}_{\mathrm{CDK}-\mathrm{EPI}}=144 \times \mathrm{SCr} / 0.7^{-1.209} \times 0.993^{\mathrm{age}}$

- If male and if $\mathrm{SCr} \leq 0.9 \mathrm{mg} / \mathrm{dl}$ :

$\mathrm{GFR}_{\mathrm{CDK}-\mathrm{EPI}}=141 \times \mathrm{SCr} / 0.9^{-0.411} \times 0.993^{\mathrm{age}}$

- If male and if $\mathrm{SCr}>0.9 \mathrm{mg} / \mathrm{dl}$ :

GFR CDK-EPI $=141 \times \mathrm{SCr} / 0.9^{-1.209} \times 0.993^{\text {age }}$

Cockcroft-Gault formula [8]:

$\mathrm{GFR}_{\mathrm{C}-\mathrm{G}}=[140$-age(years) $] \mathrm{x}$ body weight $(\mathrm{Kg}) / 72 \mathrm{x} \mathrm{SCr}$ $(\mathrm{mg} / \mathrm{dl})$ ( $\mathrm{x} 0.85$ if female)

Acute renal failure was defined as a $0.5 \mathrm{mg} / \mathrm{dl}$ increase in $\mathrm{SCr}$ if the baseline serum creatinine was $\leq 1.9 \mathrm{mg} / \mathrm{dl}$, an 1.0 $\mathrm{mg} / \mathrm{dl}$ increase in serum creatinine if the baseline serum creatinine was 2.0 to $4.9 \mathrm{mg} / \mathrm{dl}$, and a $1.5 \mathrm{mg} / \mathrm{dl}$ increase in $\mathrm{SCr}$ if the baseline serum creatinine was $\geq 5.0 \mathrm{mg} / \mathrm{dl}$ [9]. Age and sex were recorded, and weight was measured soon after admission. Blood samples for determination of SCr, haemoglobin and total protein, were drawn after overnight fasting at the time of admission. SCr assays were performed using the Jaffé method on a Hitachi Modular (Roche Diagnostics, Mannheim, Germany). Mean systolic and diastolic blood pressure (SBP and DBP) were calculated from the mean of 3 values recorded at the time of admission. The treatment given during the admission, including dialysis sessions, was recorded.

Patients were classified into different types of CRS [1]. Type 1 was defined as acute cardiac decompensation leading to kidney injury, type 2 as CHF leading to worsening renal function, type 3 as acute kidney injury leading to cardiac dysfunction, type 4 as chronic kidney disease (CKD) leading to $\mathrm{CHF}$, and type 5 as systemic conditions leading to both cardiac and renal dysfunction. Patients who died during admission and those with advanced cancer were excluded.

\section{Statistical Analysis}

Data were expressed as mean $\pm \mathrm{SD}$ or as percentage. Two-way ANOVA was used to compare parametric continuous variables, while the Kruskal-Wallis test was used to compare nonparametric continuous variables. The Chisquare test was used for estimating the occurrence of categorical variables. All $\mathrm{p}$ values were two-tailed, with statistical significance defined as $\mathrm{p}<0.05$. Statview for Windows (version 3.0, SAS Institute Inc. San Francisco, CA) was used for the calculations.

\section{RESULTS}

Out of 2,998 patients who were discharged form our unit in the study period, $438(14.6 \%)$ were diagnosed with CRS. The mean age of this sample population was $80 \pm 8$ years, with 222 male patients (50.6\%), $321(73.2 \%)$ smokers, 229 $(52.2 \%)$ diabetic patients, $207(47.2 \%)$ with clinical history of acute myocardial infarction (MI), 167 (38.1\%) with chest

Table 1. Demographic, Anthropometric and Biochemical Data of the 5 types of Cardiorenal Syndrome

\begin{tabular}{|c|c|c|c|c|c|c|}
\hline & $\begin{array}{l}\text { Type } 1 \\
n=211(48.2 \%)\end{array}$ & $\begin{array}{l}\text { Type } 2 \\
\mathrm{n}=96(21.9 \%)\end{array}$ & $\begin{array}{l}\text { Type } 3 \\
\text { n }=88(20.1 \%)\end{array}$ & $\begin{array}{l}\text { Type } 4 \\
n=29(6.6 \%)\end{array}$ & $\begin{array}{l}\text { Type } 5 \\
\text { n= } 14(3.2 \%)\end{array}$ & $\mathbf{p}$ \\
\hline Age (years) & $79.9 \pm 8.4$ & $78.5 \pm 10.3$ & $79.9 \pm 7.6$ & $79.5 \pm 9.1$ & $82 \pm 7.4$ & $\mathrm{~ns}$ \\
\hline $\operatorname{Sex}(M / F)$ & $111 / 101$ & $54 / 41$ & $45 / 43$ & $8 / 21$ & $4 / 10$ & 0.032 \\
\hline Weight (Kg) & $73.3 \pm 16.6$ & $72.9 \pm 11.4$ & $70.4 \pm 12.3$ & $71.2 \pm 12.3$ & $73.9 \pm 25.4$ & $\mathrm{~ns}$ \\
\hline $\mathrm{Hb}(\mathrm{g} / \mathrm{dl})$ & $11.1 \pm 2.0$ & $11.8 \pm 1.7$ & $11.2 \pm 2.2$ & $10.9 \pm 2.3$ & $11.3 \pm 1.4$ & ns \\
\hline Total protein $(\mathrm{g} / \mathrm{dl})$ & $6.6 \pm 0.8$ & $6.7 \pm 0.7$ & $6.5 \pm 0.8$ & $6.6 \pm 0.7$ & $6.3 \pm 0.5$ & ns \\
\hline Systolic BP (mmHg) & $135.5 \pm 25.5$ & $138 \pm 22.4$ & $132.4 \pm 24.5$ & $147.9 \pm 23.9^{\boldsymbol{\nabla}}$ & $117.1 \pm 28$ & 0.0017 \\
\hline Diastolic BP (mmHg) & $75 \pm 12.9$ & $75 \pm 11.7$ & $74.7 \pm 13.2$ & $73.2 \pm 10.9$ & $69.2 \pm 11.4$ & $\mathrm{~ns}$ \\
\hline Admission duration (days) & $9.9 \pm 6.1$ & $8.4 \pm 5.7$ & $10.4 \pm 6.3$ & $9.2 \pm 6.7$ & $16.7 \pm 9.2$ & 0.0017 \\
\hline
\end{tabular}

$\mathrm{M}=$ male. $\mathrm{F}=$ female, $\mathrm{BP}=$ blood pressure

$\checkmark$ vs $1 \mathrm{p}=0.0112$

— 5 vs $1,2,3,4 \mathrm{p}<0.05$ 
Table 2. Renal Function in the 5 Types of Cardiorenal Syndrome

\begin{tabular}{|c|c|c|c|c|c|c|}
\hline $\operatorname{GFR}_{\mathrm{MDRD} 186}\left(\mathrm{ml} / \mathrm{min} / 1.73 \mathrm{~m}^{2}\right)$ & $34 \pm 12^{*}$ & $41 \pm 12^{f}$ & $27 \pm 12$ & $31 \pm 12$ & $28 \pm 7$ & $<0.0001$ \\
\hline $\operatorname{GFR}_{M D R D 175}\left(\mathrm{ml} / \mathrm{min} / 1.73 \mathrm{~m}^{2}\right)$ & $32 \pm 12^{*}$ & $38 \pm 12^{s}$ & $25 \pm 11$ & $29 \pm 11$ & $26 \pm 7$ & $<0.0001$ \\
\hline $\operatorname{GFR}_{\text {Mayo }}\left(\mathrm{ml} / \mathrm{min} / 1.73 \mathrm{~m}^{2}\right)$ & $36 \pm 16^{*}$ & $45 \pm 16^{\circ}$ & $27 \pm 14$ & $33 \pm 15$ & $28 \pm 10$ & $<0.0001$ \\
\hline $\mathrm{GFR}_{\mathrm{C}-\mathrm{G}}(\mathrm{ml} / \mathrm{min})$ & $32 \pm 16^{*}$ & $37 \pm 15^{\varsigma}$ & $25 \pm 12$ & $29 \pm 14$ & $24 \pm 10$ & $<0.0001$ \\
\hline
\end{tabular}

GFR = glomerular filtration rate, MDRD = Modification of Diet in Renal Disease, CKD-EPI = Chronic Kidney Disease Epidemiology Collaboration, C-G = Cockcroft-Gault.

1 vs 2,3 p $<0.0001$

2 vs $3,4,5 \mathrm{p}<0.01$

Table 3. Clinical Features of Patients with Respect of the 5 types of Cardiorenal Syndrome

\begin{tabular}{|c|c|c|c|c|c|c|}
\hline Clinical Features (\%) & $\begin{array}{l}\text { Type } 1 \\
\mathrm{n}=211(48.2 \%)\end{array}$ & $\begin{array}{l}\text { Type } 2 \\
n=96(21.9 \%)\end{array}$ & $\begin{array}{l}\text { Type } 3 \\
\mathbf{n}=\mathbf{8 8}(\mathbf{2 0 . 1 \%})\end{array}$ & $\begin{array}{l}\text { Type } 4 \\
n=29(6.6 \%)\end{array}$ & $\begin{array}{l}\text { Type } 5 \\
n=14(3.2 \%)\end{array}$ & $\mathbf{p}$ \\
\hline Smoking history & 80 & 71 & 75 & 48 & 50 & 0.0016 \\
\hline Diabetes history & 50 & 53 & 56 & 48 & 57 & ns \\
\hline Ischaemic heart disease & 59 & 52 & 28 & 7 & 43 & $<0.0001$ \\
\hline Chest pain & 50 & 40 & 19 & 3 & 43 & $<0.0001$ \\
\hline Cerebrovascular disease & 27 & 30 & 42 & 27 & 3 & ns \\
\hline Peripheral arterial disease & 77 & 74 & 96 & 72 & 28 & $\mathrm{~ns}$ \\
\hline
\end{tabular}

pain, $135(30.8 \%)$ with cerebrovascular disease and 339 (77.3\%) with PAD. The most frequent type of CRS was type 1 , and type 5 was the less frequent.

Demographic, anthropometric and biochemical data of the 5 types of CRS are listed in Table 1. Age was not significantly different among the 5 CRS types; female sex and SBP were more prevalent in type $4 \mathrm{CRS}$. In contrast, SBP was lower in type 5 than in the other types. Hospital LOS was higher in type 5. Evaluation of renal function in the 5 types of CRS is shown in Table 2. SCr was lower and GFR was higher in type 2 than in the other types. The worst renal function was recorded in type 3 and 4 . Results obtained from the eGFR equations were similar, although the MAYO equation tended to overestimate the value compared with the other formulae (Table 2). Smoking history was more prevalent in types 1, 2, 3, and IHD and chest pain were more frequent in types 1 and 2 than in the other types (Table 3 ). Diuretics and nitrates were given in a greater proportion of patients with type 1 , dialysis treatment was performed in a few cases with type 3 and 4 (Table 4).

\section{DISCUSSION}

Cardiorenal syndrome defines a condition due to combined cardiac and renal dysfunction leading to the amplification of the progression of failure of the individual organs and a bad prognosis. The aging of the population, the amelioration of cardiac invasive procedures leading to a better prognosis of diseases that historically had a poor outcome have resulted in increasing number of patients with combined heart and kidney failure. Cardiorenal insufficiency is more than an association of cardiac and renal disease. Hypertension, widespread atherosclerotic vascular damage, and diabetes mellitus are significant risk factors for both heart failure and renal failure. Patients with CRS appear to depend on the interaction of neurohumoral, hemodynamic, and other less known factors [10]. In patients with heart failure, renal dysfunction can result from intrinsic renal disease, hemodynamic abnormalities, or their combination. Cardiac pump failure leads to low cardiac output and hypotension, responsible of neurohormonal activation producing both fluid retention and vasoconstriction. However, the cardiorenal relationship is more complex than the hemodynamic model alone; activation of the renin-angiotensin system, nitric oxide, reactive oxygen species, inflammation, anemia and the sympathetic nervous system should also be taken into account [11].

The association between CKD and CVD has been evaluated in an unselected community based cohort of 2,471 subjects aged 68 years [12]. Women with GFR 30-44 $\mathrm{ml} / \mathrm{min} / 1.73 \mathrm{~m}^{2}$ and men with GFR $30-50 \mathrm{ml} / \mathrm{min} / 1.73 \mathrm{~m}^{2}$ but without history of CVD had a hazard ratio for CVD of 1.51 
Table 4. Pharmacological Treatment of Patients with Respect of the 5 Types of Cardiorenal Syndrome

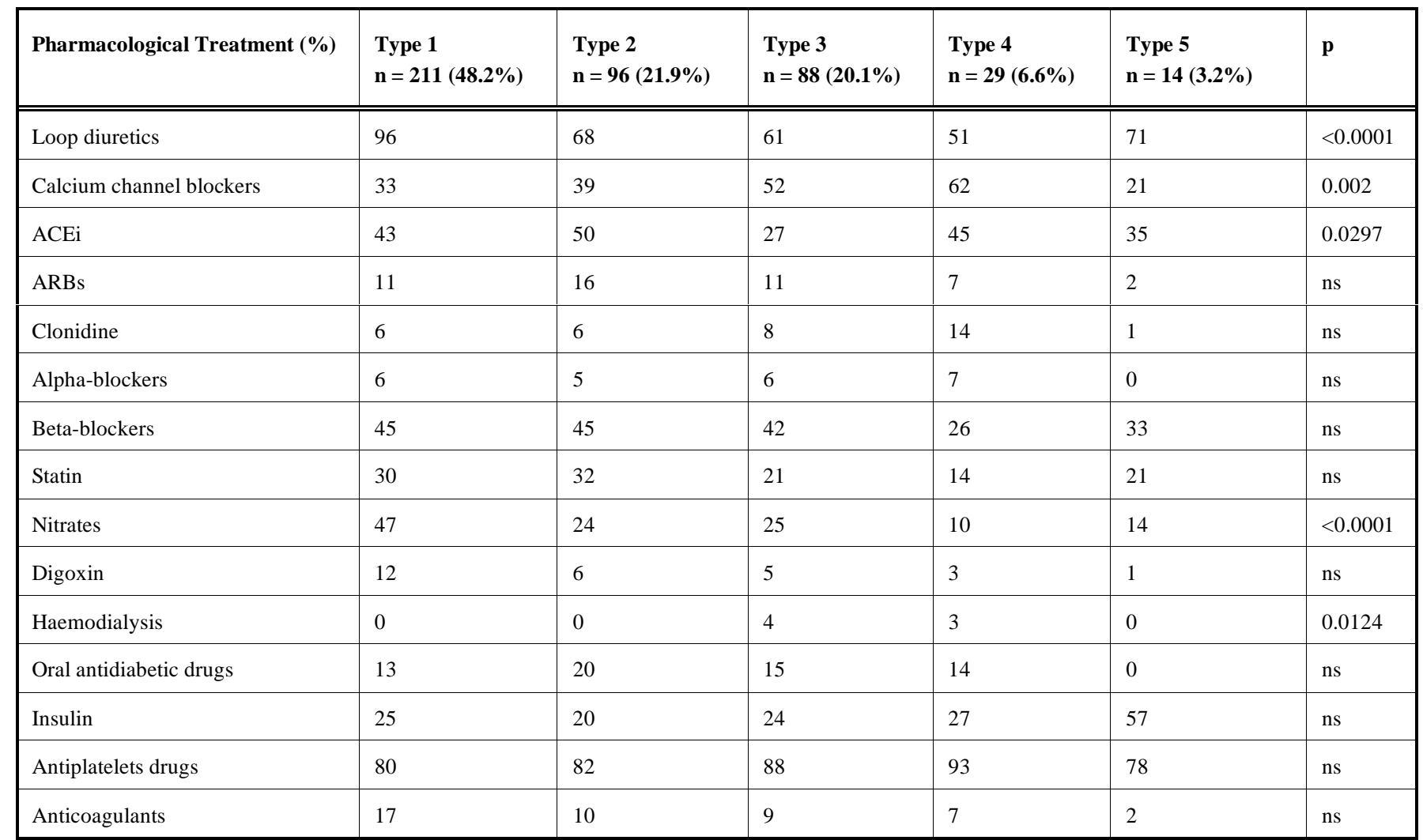

$\mathrm{ACEi}=$ angiotensin converting enzyme-inhibitors; ARBs = angiotensin receptors blockers.

that increased to 2.39 in those with CVD history [12]. Worsening of renal function is also an independent predictor of mortality in acute decompensated heart failure (ADHF) [13]. The prevalence of CRS is still a matter of debate. Between 27 and $45 \%$ of subjects admitted for acute heart failure suffered an acute worsening of renal function, with an increase in serum creatinine level $(0.3 \mathrm{mg} / \mathrm{dl})$ during hospitalization. [14].

Heywood et al. [15] reported that in 118,465 patients hospitalized for ADHF, 27.4\% had mild renal dysfunction (GFR $60-89 \mathrm{ml} / \mathrm{min} / 1.73 \mathrm{~m}^{2}$ ), $43.5 \%$ had moderate renal dysfunction (GFR 30-59 ml/min/1.73 $\mathrm{m}^{2}$ ), $13.1 \%$ had severe renal dysfunction (GFR $15-29 \mathrm{ml} / \mathrm{min} / 1.73 \mathrm{~m}^{2}$ ), and $7.0 \%$ had kidney failure (GFR $<15 \mathrm{ml} / \mathrm{min} / 1.73 \mathrm{~m}^{2}$ or chronic dialysis). Smith et al. published a systematic review of 16 studies including 80,098 hospitalized and non-hospitalized $\mathrm{CHF}$ patients, and found that mortality increased by $7 \%$ for every $10 \mathrm{ml} / \mathrm{min}$ reduction in GFR evaluated at baseline [16]. Damman et al. [17] evaluated the relationship between worsening renal failure and mortality in 18,634 patients enrolled in 8 studies. Worsening renal failure was reported to develop in $25 \%$ of cases, and it was associated with a higher risk for mortality and hospitalization. In the present study, over a 30-month period, we identified 438 CRS cases out of 2,998 patients discharged form our unit (prevalence $=14.6$ $\%$ and incidence $=14.6$ patients $/$ month $)$.

Diagnosis of CRS is difficult, since physicians have to consider different interfering factors such as intravascular volume, use of non-steroidal anti-inflammatory drugs
(NSAIDs), and drugs acting on the renin angiotensin aldosterone system (RAAS). Distinction between impaired renal function due to heart failure and underlying kidney disease is very important, since it allows classification of patients in the different types of CRS. In order to correctly classify our population we analyzed the records to detect urine sediments, with haematuria, casts or proteinuria and/or small kidneys on ultrasonography, features that suggest underlying renal disease.

Although the frequency of IHD in CKD patients is high, the use of cardioprotective drugs in this population is low. A study [18] of more than 3,000 dialysis patients with a 2-year follow-up, calculated an incidence of acute coronary syndromes of 29/1,000 person-years. Nevertheless, cardioprotective drugs were used in less than $50 \%$ of patients with known IHD, but they were not associated with significant benefit. A similar result was reported in 902 dialysis patients aged $\geq 65$ years, admitted with MI. The authors concluded that elderly dialysis patients had excessively high mortality, and low use of standard cardioprotective therapies, such as angiotensin converting enzyme-inhibitors (ACEi) and/or angiotensin receptors blockers (ARBs), statins and betablockers, but it remains uncertain whether this could be attributable to a low use of cardiovascular medications. On the other hand, only ACEi use was associated with reduced risk of death [19]. Again, Berger et al. [20] found that aspirin, beta-blockers and ACEi were less likely to be administered to dialysis patients than the non-uremic ones. However, ana- 
lyzing 145,740 non-uremic patients and 1,025 dialysis subjects admitted for MI, the benefit of these therapies on 30day mortality was similar in the 2 groups [20]. Treatment for ADHF is frequently complicated by worsening renal function, drawing the picture of type 1 CRS. Results from the Evaluation Study of Congestive Heart Failure and Pulmonary Artery Catheterization Effectiveness trial showed that, in the group of patients with hemoconcentration, the dose of loop diuretics was higher, renal function was worse, and 180-day mortality was lower compared with the group without hemoconcentration [21]. Felker et al. [22] conducted a prospective, double blind, randomized trial in 308 subjects with ADHF treated with intravenous furosemide. Patients were randomly assigned to receive low-dose of loop diuretic, equal to their daily oral dose or high-dose, equal to 2.5 times their total oral dose, and to furosemide either by intravenous bolus every $12 \mathrm{~h}$ or by continuous intravenous infusion. The mean change in the $\mathrm{SCr} 72 \mathrm{~h}$ after starting furosemide therapy was similar comparing bolus vs continuous and lowdose vs high-dose, and the mean values of $\mathrm{SCr}$ increase was between 0.04 and $0.08 \mathrm{mg} / \mathrm{dl}$ [22].

Inhibition of the RAAS with ACEi or ARBs is a well established treatment for CHF, being associated with symptomatic improvement, reduced hospitalization and increased survival. We should take into consideration that CRS could represent an effect of physician intervention, since ACEi and ARBs could decrease renal function, increasing $\mathrm{SCr}$ values, even if they improve outcome [23]. A different therapeutic approach could influence renal function as well, since it has been shown that resynchronization therapy can ameliorate renal function in subjects with GFR lower than 30 $\mathrm{ml} / \mathrm{min} / 1.73 \mathrm{~m}^{2}$ [24]. Blasco et al. [25] evaluated 751 patients with acute MI admitted to a coronary care unit (CCU). Subjects with GFR lower than $60 \mathrm{ml} / \mathrm{min} / 1.73 \mathrm{~m}^{2}$ were older, had greater comorbidities, congestive heart failure and higher mortality than those with GFR equal or greater than 60 $\mathrm{ml} / \mathrm{min} / 1.73 \mathrm{~m}^{2}$. Renal impairment was an independent predictor of mortality during CCU stay. On the other hand, among patients with diabetes and CVD, the presence of CHF acts as a trigger for detecting CKD [26].

Our study showed that diuretics were taken by $96 \%$ of type 1 CRS patients and ACEi were taken by nearly half of subjects with CRS type 1,2 and 3, and nearly one third of those with CRS type 3 and 4. In contrast, ARBs were recorded in lower percentages of patients.

Carnevale et al. [27] reported that Mayo Clinic Quadratic equation could overestimate true renal function in older adult patients, since GFR $_{\text {MAYO }}$ had a mean value of 158 $\mathrm{ml} / \mathrm{min} / 1.73 \mathrm{~m}^{2}$, nearly $100 \mathrm{ml} / \mathrm{min} / 1.73 \mathrm{~m}^{2}$ higher, compared with creatinine clearance evaluated with $24-\mathrm{h}$ urine collection that was measured to be $56.6 \mathrm{ml} / \mathrm{min} / 1.73 \mathrm{~m}^{2}$. Our results are in agreement with these results since $\mathrm{GFR}_{\text {Mayo }}$ recorded the highest values in different subtypes of CRS.

Our study has limitations. First, the optimal evaluation of renal function would require subjects in a stable condition. In our study, we evaluated patients according to the criteria by Hou et al. [9] and calculated GFR in order to compare all different CRS subtypes. Second, we did not consider that patients could move across different CRS subtypes during the course of the disease. Moreover, we did not systemati- cally check for laboratory biomarkers, but only when the physician, on admission, needed to improve diagnostic accuracy. Third, we do not report detailed functional and structural cardiac assessment by echocardiography. However, our aim was merely to clinically characterize the 5 types of CRS, thus helping physicians to deal with elderly co-morbid patients and recognize CRS in everyday clinical practice. On the other hand it should be underlined that the number of patients in the different types of CRS is low especially in type 4 and 5, and we cannot exclude inaccuracies in definitions. Finally, our study has all the disadvantages of a retrospective design.

To the best of our knowledge, this is the first study that made an attempt to diagnose CRS in a large sample of patients consecutively discharged from an Internal Medicine ward. This represents the "real life world" of general hospital patients. As suggested by others [28], we also believe that prevention of CRS may play a key role although the treatment targets may not be well defined.

The management of intravascular volume, blood pressure and cardiac output, renal haemodynamic, anaemia, and intrinsic renal disease are essential and in order to preserve the equilibrium of each individual patient often necessitating a multidisciplinary approach. The overall goals of management of these patients should be to normalize volume status while avoiding overdiuresis and to control renal dysfunction, and to implement pharmacological and device therapy to improve patient outcomes [29]. Drugs that are commonly prescribed in heart failure, such ACEi, beta-blockers, and spironolactone, are rather underused in CRS although it has been suggested that these drugs could be useful in CKD [30]. On the other hand patients with heart and renal failure have been underrepresented in trials. Therefore little evidence is available to guide physicians in the optimal management of patients with both conditions [31].

Physicians should pay attention in recognizing the coexistence of heart and renal failure, and GFR should be always calculated in order to detect CKD. In fact, early recognition of CRS could allow careful follow-up and strategies of management of these high risk patients.

\section{DISCOLOURS}

This text has been seen and approved by all authors and it is not under consideration for publication elsewhere in a similar form, in any language, except as an abstract.

\section{CONFLICT OF INTEREST}

F. Fabbian, M. Pala, A. De Giorgi, A. Scalone, C. Molino, F. Portaluppi, R. Manfredini, had no conflict of interest; D.P. Mikhailidis has given talks, attended conferences and participated in advisory boards and trials sponsored by Merck, Sharp \& Dohme and Genzyme.

\section{ACKNOWLEDGEMENTS}

None declared.

\section{REFERENCES}

[1] Ronco C, McCullogh P, Anker SD, et al. Cardiorenal syndromes: report from the consensus conference of the Acute Dialysis Quality Initiative. Eur Heart J 2010; 31: 703-11. 
[2] Bongartz LG, Cramer MJ, Doevendans PA, Joles JA, Braam B. The severe cardiorenal syndrome: "Guyton revisited". Eur Heart J 2005; 26: 11-7.

[3] Dickstein K, Cohen-Solal A, Filippatos G, et al. ESC guidelines for the diagnosis and treatment of acute and chronic heart failure. Eur Heart J 2008; 29: 2388-442.

[4] Levey AS, Greene T, Kusek JW, Beck GJ. A simplified equation to predict glomerular filtration rate from serum creatinine. J Am Soc Nephrol 2000; 11: 155A.

[5] Levey AS, Coresh J, Greene T, et al. Chronic kidney disease epidemiology collaboration: using standardized serum creatinine values in the modification of diet in renal disease study equation for estimating glomerular filtration rate. Ann Intern Med 2006; 145 : 247-54.

[6] Rule AD, Larson TS, Bergstralh EJ Slezak JM, Jacobsen SJ, Cosio FG. Using serum creatinine to estimate glomerular filtration rate: accuracy in good health and in chronic renal kidney disease. Ann Intern Med 2004; 141: 929-37.

[7] Levey AS, Stevens LA, Schmid CH, CKD-EPI (Chronic Kidney Disease Epidemiology Collaboration) et al. A new equation to estimate glomerular filtration rate. Ann Intern 2009; 150: 604-12.

[8] Cockcroft DW, Gault MH. Prediction of creatinine clearance from serum creatinine. Nephron 1976; 16: 31-41.

[9] Hou SH, Bushinsky DA, Wish JB, Cohen JJ, Harrington JT. Hospital-acquired renal insufficiency: a prospective study. Am J Med 1983; 74: 243-8.

[10] Gil P, Justo S, Castilla MA, Criado C, Caramelo C. Cardio-renal insufficiency: the search for management strategies. Curr Opin Nephrol Hypertens 2005;14:442-7.

[11] Longhini C, Molino C, Fabbian F. Cardiorenal syndrome: still not a defined entità. Clin Exp Nephrol 2010; 14:12-21.

[12] Parikh NI, Hwang SJ, Larson MG, Levy D, Fox CS. Chronic kidney disease as a predictor of cardiovascular disease (from the Framingham Heart Study). Am J Cardiol 2008; 102: 47-53.

[13] Breidthardt T, Socrates T, Noveanu M, et al. Effect and clinical prediction of worsening renal function in acute decompensated heart failure. Am J Cardiol 2011; 107: 730-55.

[14] Forman DE, Butler J, Wang Y, et al. Incidence, predictors at admission, and impact of worsening renal function among patients hospitalized with heart failure. J Am Coll Cardiol 2004; 43: 61-7.

[15] Heywood JT, Fonarow GC, Costanzo MR, et al. High prevalence of renal dysfunction and its impact on outcome in 118,465 patients hospitalized with acute decompensated heart failure: a report from the ADHERE database. J Card Fail 2007; 13: 422-30.

[16] Smith GL, Lichtman JH, Bracken MB, et al. Renal impairment and outcomes in heart failure: systematic review and meta-analysis. J Am Coll Cardiol 2006; 47: 1987-96.

[17] Damman K, Navis G, Voors AA, et al. Worsening renal function and prognosis in heart failure: systematic review and meta-analysis. Card Fail 2007; 13: 599-608.
[18] Trespalacios FC, Taylor AJ, Agodoa LY, Abbott KC. Incident acute coronary syndromes in chronic dialysis patients in the United States. Kidney Int 2002; 62: 1799-805.

[19] Winkelmayer WC, Charytan DM, Levin R, Avorn J. Poor shortterm survival and low use of cardiovascular medications in elderly dialysis patients after acute myocardial infarction. Am J Kidney Dis 2006; 47: 301-8.

[20] Berger AK, Duval S, Krumholz HM. Aspirin, beta-blocker, and angiotensin converting enzyme inhibitor therapy in patients with end-stage renal disease and an acute myocardial infarction. J Am Coll Cardiol 2003; 42: 201-8.

[21] Testani JM, Chen J, McCauley BD, Kimmel SE, Shannon RP. Potential effects of aggressive decongestion during the treatment of decompensated heart failure on renal function and survival. Circulation 2010; 122: 265-72.

[22] Felker GM, Lee KL, Bull DA, et al. Diuretic strategies in patients with acute decompensated heart failure. N Engl J Med 2011; 364 : 797-805.

[23] Ljungman S, Kjekshs J, Swedberg K. Renal function in severe congestive heart failure during treatment with enalapril (the Cooperative North Scandinavian Enalapril Survival Study [Consensus] Trial). Am J Cardiol 1992; 70: 479-87.

[24] Adelstein EC, Shalaby A, Saba S. Response to cardiac resynchronization therapy in patients with heart failure and renal insufficiency. Pacing Clin Electrophysiol 2010; 33: 850-9.

[25] Blasco L, Sanjuan R, Carbonell N. Estimated glomerular filtration rate in short-risk stratification in acute myocardial infarction. Cardiorenal Med 2011; 1: 131-8.

[26] Whaley-Connell A, Bomback AS, McFarlane SI, et al. Diabetic cardiovascular disease predicts chronic kidney disease awareness in the Kidney Early Evaluation Progam. Cardiorenal Med 2011; 1: 45-52.

[27] Carnevale V, Pastore L, Camaioni M, et al. Estimate of renal function in oldest old inpatients by MDRD study equation, Mayo Clinic equation and creatinine clearance. J Nephrol 2010; 2010; 23: 306-13.

[28] McCullough PA, Haapio M, Mankad S, et al. Acute Dialysis Quality Initiative (ADQI) Consensus Group. Prevention of cardio-renal syndromes: workgroup statements from the 7th ADQI Consensus Conference. Nephrol Dial Transplant 2010 25: 1777-84.

[29] Boerrigter G, Burnett JC Jr. Cardiorenal syndrome in decompensated heart failure: prognostic and therapeutic implications. Curr Heart Fail Rep 2004; 1: 113-20.

[30] Ruilope LM, Salvetti A, Jamerson K, et al. Renal insufficiency and intensive lowering of blood pressure in hypertensive participants of the Hypertension Optimal Treatment (HOT) study. J Am Soc Nephrol 2001; 12: 218-25.

[31] Coca SG, Krumholz HM, Garg AX, Parikh CR. Underrepresentation of renal disease in randomized controlled trials of cardiovascular disease. JAMA 2006; 296: 1377-84.

This is an open access article licensed under the terms of the Creative Commons Attribution Non-Commercial License (http://creativecommons.org/licenses/ by-nc/3.0/) which permits unrestricted, non-commercial use, distribution and reproduction in any medium, provided the work is properly cited. 